\title{
Comparisons on Different Liquid Crystals Doped with Various Sized Gold Nanoparticles for Nonvolatile Memory Effects
}

Marino $\mathrm{L}^{1 *}$, Koduru $\mathrm{HK}^{1}$, Marino $\mathrm{S}^{2}$, Facal Marina $\mathrm{P}^{3}$, Wang $\mathrm{D}^{4}$, Dabrowski $\mathrm{R}^{5}$ and Scaramuzza

${ }^{1}$ Department of Physics, University of Calabria, Ponte P. Bucci Cubo 33B, 87036 Rende (CS), Italy

${ }^{2}$ SIMAU Università Politecnica delle Marche, Via Brecce Bianche, 60131 Ancona, Italy

${ }^{3}$ Future Industries Institute, University of South Australia, Mawson Lakes Campus, Adelaide, SA 5095, Australia

${ }^{4}$ Department of Civil, Environmental and Chemical Engineering, School of Engineering, RMIT University, Melbourne, VIC, Australia

${ }^{5}$ Department of Chemistry, Military University of Technology, PL-00-908 Warszawa, Poland

${ }^{6}$ Department of Physics, University of Calabria, Ponte P. Bucci Cubo 33B, 87036 Rende (CS), Italy

Received: December 20, 2016; Accepted: January 03, 2017; Published: February 04, 2017

*Corresponding author: Lucia Marino, University of Calabria Ponte P. Bucci Cubo 33B 87036 Rende (CS), Italy, Tel: +39 0984 4911 ;Fax: +39 0984 49 4401;E-mail: lucia.marino@fis.unical.it

\begin{abstract}
The demand for ever more efficient non-volatile memory devices has triggered intense research into new materials and novel device architectures. In this context, nano-composite materials obtained by dispersing metallic nano-particles in liquid crystal materials, seems to be particularly promising. In this work we investigated non-volatile memory effects in two different orthoconic smectic liquid crystal mixtures with and without the addition of two different kind of polymer capped gold nanoparticles by means of broadband dielectric spectroscopy, which is a powerful method to study molecular dynamics and molecular mobility of various materials reflected in the relaxation processes over a wide frequency range. The dielectric measurements have been performed by applying bias during spectra aquisition or by applying the condition potential before the start of spectra aquisition, in order to confirm how the electric field induces charge transfer from the liquid crystal molecules to the polymeric capping of the gold nanoparticles acting as a trap for ionic charges. The results underline the importance of the structure of the host liquid crystal, the size of the nanoparticles but, above all, the kind of the polymer coating on the gold nanoparticles. The observed memory effect is of paramount importance in development of digital nonvolatile memory devices.
\end{abstract}

Keywords: Liquid Crystals; Nanotechnology; Dielectric Spectroscopy

\section{Introduction}

By its very nature, nanotechnology is of immense academic and industrial interest as it enables the creation and exploitation of materials with structural features with at least one dimension limited to the range between 1 and $100 \mathrm{~nm}$. Most importantly, the properties of nano-structured materials can be significantly different from those of atoms or bulk materials in many aspects.

An important subset of nano-structured materials is represented by the so-called nano-composites consisted of nano particles dispersed in a continuous three-dimensional matrix. In this context are of particular interest the nano-composites obtained by dispersing metallic nano-particles in liquid crystal materials. Liquid crystals are a phase of matter whose order is intermediate between that of a liquid and that of a crystal (mesophases). Their molecules are often shaped like rods or plates or some other forms that encourage them to align collectively along a certain direction. The order of liquid crystals can be manipulated with mechanical, magnetic or electric forces. For this reason they are historically used in display technology and other electrooptic devices [1]. More recently liquid crystals by their very nature are suitable for matrix-guided synthesis and self-assembly of nanoscale materials [2-4]. Since liquid crystals are anisotropic materials they provide excellent supports for selfassembly of nano-particles into larger ordered superstructures. Of particular interest are antiferroelectric nano-particle doped liquid crystal mixtures, which may exhibit nonvolatile memory effects. In the past years the bistability or memory effect has been demonstrated in Deformed Helix Ferroelectric Liquid Crystals (DHFLCs) doped with Gold Nano-Particles (GNPs), in which the long nonvolatile memory effect has been observed probably as a result of the electric field induced charge transfer effect from liquid crystal molecules to the GNPs and the stabilization of the helix deformation process [3]. As reported in our previous work, furthermore, the capture of ions/charges inside the polymeric coatings on the GNP surfaces increased the resistivity of the GNPdoped liquid crystal composites [4]. Memory effects have been observed in both pure orthoconic smectic liquid crystal mixture and those doped with GNPs, indicative of the importance of the liquid crystal host. However, the characteristic of the memory effects has been found dependent on the chemical nature and properties of both the GNPs and liquid crystal molecules. We 
reported that the presence of GNPs enhanced the memory effects to be visible after several days. The stabilization of the memory effect is probably due to the polymeric coatings of the GNPs acting as traps for ionic charges, from which a large reduction of complessive conductivity was derived [4].

Here we present the nonvolatile memory effects of two orthoconic smectic liquid crystal mixtures doped with Gold Nanoparticles (GNPs) having different sizes and different kind of polymer capping. These measurements reveal that the memory effect is strongly dependent on the size of the nanoparticles but, above all, on the kind of polymer coating.

\section{Methods and Materials}

The mixtures of two orthoconic liquid crystals, W129 and W182, synthesized by R. Dabrowski's group at the Military University of Technology, in Warsav, (Poland), were used for the present study, which exhibited both ferroelectric and antiferroelectric smectic $\mathrm{C}$ phases. The liquid crystal mixtures were doped with the polymer coated GNPs with different diameters, suspended in ultrapure water. The Percentage of nanoparticles within the liquid crystal cell is $0.02 \mathrm{wt} / \mathrm{wt} \%$ of liquid crystal. The W129 phase sequence, obtained from DSC measurements, was $\mathrm{Cr}-13 / 15^{\circ} \mathrm{C}-\mathrm{SmCa}^{*}-84.5^{\circ} \mathrm{C}-\mathrm{SmC}^{*}-102.3^{\circ} \mathrm{C}$ $\mathrm{SmA}^{*}-117 / 125.2^{\circ} \mathrm{C}$-Iso The $\mathrm{W} 182$ phase sequence, obtained from DSC measurements, was SmCa* $100.5^{\circ} \mathrm{C}-\mathrm{SmC}^{*}-116^{\circ} \mathrm{C}-$ SmA - $123.3 / 126.2^{\circ} \mathrm{C}$ - Iso Japanese planar aligned commercial cells (EHC Ltd, Tokyo, Japan) with thickness of $(2.0 \pm 0.2) \mu \mathrm{m}$ and an ITO resistance of $100 \Omega$ / ? were used. After the GNPs doped LC mixtures were introduced into the cells via capillary suction, the cells were heated in order to remove water via evaporation. The dielectric measurements were carried out on an EG\&G 273A galvanostat-potentiostat/impedentiometer controlled by the impedance software M398 in order to acquire the real and imaginary part of impedance in the frequency range of $1 \mathrm{~Hz}-100$ $\mathrm{kHz}$ with a maximum applied voltage of $20 \mathrm{mv}$ (RMS). One set of measurements were made by applying bias and the other by applying a condition potential for 900 seconds before acquiring impedance spectra.

\section{Report of Gold Samples}

Hydrogen tetrachloroaurate(III) tetrahydrate (haucl $44 \mathrm{H}_{2} \mathrm{O} 99.999 \%$ trace metals basis) product number 254169, Trisodium citrate dihydrate $\left(\mathrm{Na}_{3} \mathrm{C}_{6} \mathrm{H}_{5} \mathrm{O}_{7} \geq 99 \%\right.$ FG product number W3 26 were purchased from Aldrich and silver nitrate $\left(\mathrm{agno}_{3}\right.$ 99.999\%) was purchased from Alfa Aesar. All these chemicals were used as received. All glassware was cleaned with aqua regia (3:1 v/v hcl (37\%): $\mathrm{HNO}_{3}(65 \%)$ solutions) and then rinsed thoroughly with Milli-Q water before use. The aqueous solution of haucl ${ }_{4}(1 \mathrm{wt} \%)$ was prepared and stored atca. $4^{\circ} \mathrm{C}$ before use. Disulfide-functionalized $\mathrm{MEO}_{2} \mathrm{MA}_{90}$-co-OEGMA 10 copolymers and OEGMA homopolymers, polyoegma with Molecular Weight (MW) of ca. $25000 \mathrm{~g} / \mathrm{mol}$ were synthesized via A RP initiated with using 2,2'-dithiobis[1-(2-bromo-2-methylpropionyloxy) ethane] (brc $\left.\left(\mathrm{CH}_{3}\right) 2 \mathrm{COO}\left(\mathrm{CH}_{2}\right)_{2} \mathrm{~S}\right)_{2}$ [5]. The $\mathrm{MEO}_{2} \mathrm{MA}_{90}$-co-OEGMA copolymers show a lower solution temperature LCST in water around $40^{\circ} \mathrm{C}$ in between the LCST values of the homopolymers of $\mathrm{MEO}_{2} \mathrm{MA}\left(\mathrm{LCST}=27^{\circ} \mathrm{C}\right)$ and OEGMA (LCST $=93^{\circ} \mathrm{C}[6]$.

Monodisperse, quasi-spherical gnps with sizes of 12 $\mathrm{nm}$ were synthesized via silver (I)-assisted citrate reduction of haucl $_{4}$ in water according to the method reported by Xia, et al. [7]. Monodispersed, quasi-spherical gnps with sizes of $36 \mathrm{~nm}$ were synthesized according to a modified method reported by Zhang, et al. [8]. The resulting gnps were subsequently coated with the $\mathrm{MEO}_{2} \mathrm{MA}_{90}$-co-OEGMA 10 copolymer and polyoegma brushes, respectively, via ligand exchange. Typically, $50 \mathrm{ml}$ of the resulting citrate-stabilized gnps were added dropwise to $1 \mathrm{ml}$ of the aqueous solutions of polyoegma and $\mathrm{MEO}_{2} \mathrm{MA}_{90}$-Co-OEGMA copolymers $(50 \mathrm{mg} / \mathrm{ml})$, respectively and incubated overnight under gente stirring. In order to completely remove free polymers, the aqueous dispersions of the resulting gnps were purified by repetition of the cycle of centrifugation, decanting supernatant, and redispersion in water till the supernatants exhibit no thermoresponsivity. The resulting gnps were denoted as Aun@ $\mathrm{MEO}_{2} \mathrm{MA}_{90}$-Co-OEGMA ${ }_{10}$, where $\mathrm{n}$ represents the GNP core sizes; it being 12 (see Figure 1) and 32(see Figure 2).

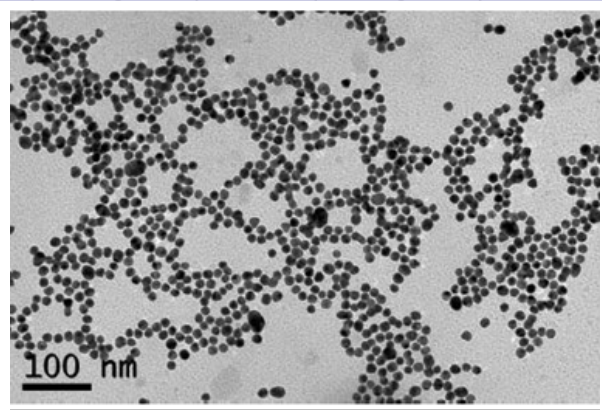

Figure 1: Characterization of Au008 nanoparticles by TEM. The resulting diameter is about $12 \mathrm{~nm}$.

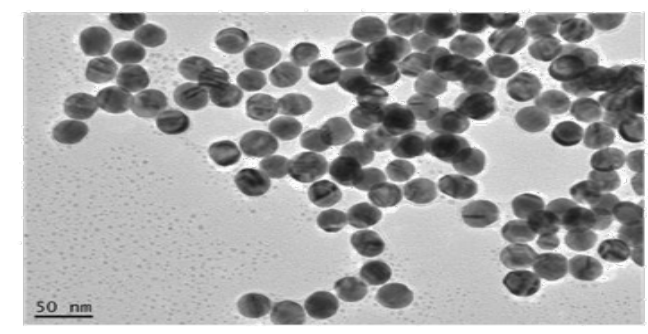

Figure 2: Characterization of Au006 nanoparticles by TEM. The resulting diameter is about $30 \mathrm{~nm}$.

\begin{tabular}{|l|l|l|}
\hline $\begin{array}{l}\text { SAMPLE } \\
\text { DESIGNATION }\end{array}$ & Au Nps & Au @coated Nps size \\
\hline $\begin{array}{l}\mathrm{Au}_{12} @ \mathrm{MEO}_{2} \mathrm{MA}_{90}-\mathrm{co}- \\
\mathrm{pOEGMA}_{10}\end{array}$ & $\mathrm{Au008}$ & $\begin{array}{l}\mathrm{Au}_{008} @ \mathrm{MEO}_{2} \mathrm{MA}_{90}-\mathrm{co}- \\
\mathrm{pOEGMA}_{10}\end{array}$ \\
\hline $\begin{array}{l}\mathrm{Au}_{32} @ \mathrm{MEO}_{2} \mathrm{MA}_{90}-\mathrm{Co}- \\
\mathrm{pOEGMA}_{10}\end{array}$ & $\begin{array}{l}\mathrm{Au}_{006} @ \mathrm{MEO}_{2} \mathrm{MA}_{90}-\mathrm{co}- \\
\mathrm{pOEGMA}_{10}\end{array}$ \\
\hline
\end{tabular}


The GNPs coated with the polyOEGMA brushes were denoted as Aun@polyOEGMA.

\begin{tabular}{|l|l|l|}
\hline SAMPLE DESIGNATION & $\mathrm{Au}$ Nps & $\mathrm{Au} @$ coated Nps size \\
\hline $\mathrm{Au}_{12} @$ pOEGMA & $\mathrm{Au} 011$ & $\mathrm{Au}_{011} @$ pOEGMA \\
\hline $\mathrm{Au}_{36} @ \mathrm{pOEGMA}$ & $\mathrm{Au} 012$ & $\mathrm{Au}_{012} @$ pOEGMA \\
\hline
\end{tabular}

\section{Results and Discussions}

\section{Results with W129 Liquid Crystal}

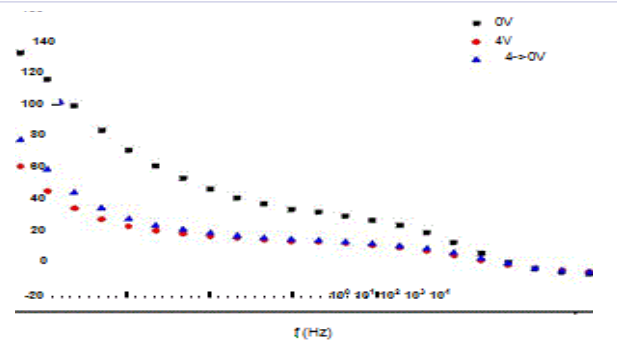

Figure 3: Dielectric permittivity as a function of frequency at $95^{\circ} \mathrm{C}$ at $0 \mathrm{~V}$, at $4 \mathrm{~V}$, again $0 \mathrm{~V}(4->0 \mathrm{~V})$, of pure $\mathrm{W} 129$.

indicates that pure W129 shows a memory effect probably due to order/structural changes induced by applied external voltage. The dielectric permittivity $\left(\varepsilon^{\prime}\right)$ acquired at $95^{\circ} \mathrm{C}$ (during ferroelectric phase), varies with frequency. The change in the bias voltage of measuring field from 0 to $4 \mathrm{~V}$ makes the dielectric permittivity decline to a minimum, which is a result of the suppression of phason (Goldstone) mode related to phase fluctuation of the molecules [9]. Again on applying $0 \mathrm{~V}$ bias the permittivity appears in an intermediate state between curves with bias different from zero and initial condition before applying bias. This indicates a non-negligible memory even in the absence of GNPs.

When a dc potential is applied before the experiment starts, that is, the ac excitation turned off, a conditioning of the sample occurs. In figure 4

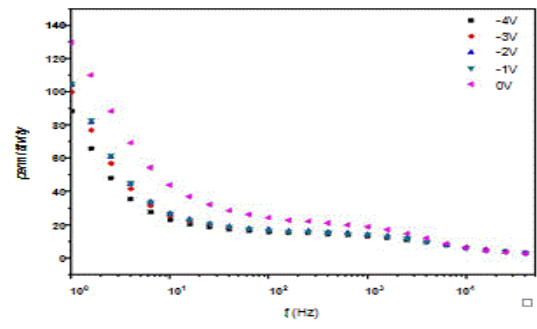

Figure 4: Dielectric permittivity as a function of frequency at $95^{\circ} \mathrm{C}$ after condition dc potential, from -4 to $-1 \mathrm{~V}$ and again $0 \mathrm{~V}(-1->\mathrm{V})$ of W129.

are represented many cases with different values of condition potential in comparison with the initial state. In are showed curves obtainedcoated GNPs with different diameters, applying negative potentials, returning step to step from $-4 \mathrm{~V}$ to $0 \mathrm{~V}$. The last results suggest that the system is influenced by the potential values and tends to move closer starting conditions. Figure 5 shows the permittivity values of W129 doped with 12 nm GNPs coated with polyOEGMA brushes. One can observe the memory effect in the frequency range between $10-104 \mathrm{~Hz}$ (Figure 5A). From imaginary part acquired at 0V (Figure 5B), at $4 \mathrm{~V}$ (Figure 5C) and finally again at $0 \mathrm{~V}$ (Figure 5D), one can see the shift at a lower frequency of the Goldstone Mode (hn1) when we apply $4 \mathrm{~V}$ and the shift at higher frequency when the bias is removed (4- $>0 \mathrm{~V}$ ). A reduction of the dielectric strength is also visible. The fit analysis, carried out in each condition with and without bias, indicates a Cole-Cole mode as one can learnt from the values of parameters a and b listed in Table 2 and 3. The conductivity value increases with the bias applied, while it returns to a lower value after turnoff of the applied voltage, it returns to a lower value (see Table 1 ).
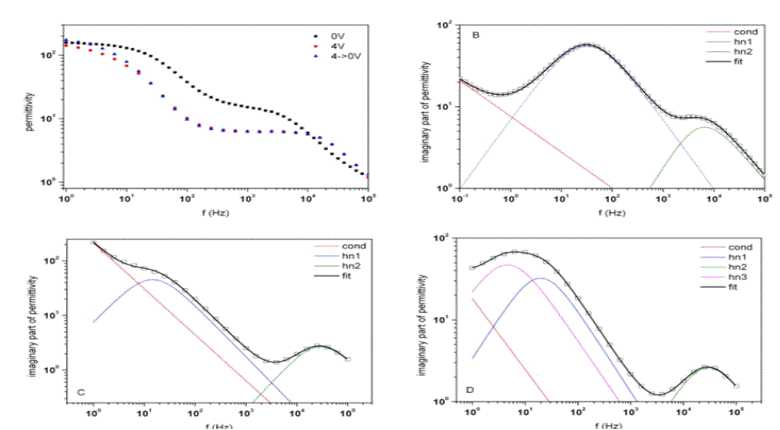

Figure 5: Dielectric permittivity as a function of frequency at $95^{\circ} \mathrm{C}$ at 0V, at 4V, again 0V (4 - > 0V), of W129 doped with Au $\mathrm{u}_{12} @$ polyOEGMA (A). Imaginary part of permittivity at $0 \mathrm{~V}$ (B), $4 \mathrm{~V}(\mathrm{C}), 4->0 \mathrm{~V}$ (D).

In figure 6 we observe one gap from $-4 \mathrm{~V}$ to $-3 \mathrm{~V}$ and the other from -3 to $-1 \mathrm{~V}$ when the system slowly approaches the precondition potential values.

The situation is substantially different when we use 30 nm GNPs coated with polyOEGMA brushes. The memory effect is visible in the range of frequency from $10^{2}$ to $10^{3} \mathrm{~Hz}$, while the permittivity values are higher in the system in which the bias is applied and in the system after the removal of bias (Figure 7A). Here the memory effect is related to the inhibition of two modes, while it should be worthwhile to note that the inhibition of the Goldstone mode is a direct consequence of the application of a bias. It is plausible to suppose that bigger nanoparticles, once being polarized, induce the formation of larger and hardly excitable clusters.

The shift at lower frequency of the Goldstone mode and Soft mode (hn2) is present (Figure 7B and 7C) and the dielectric increment is quite larger in both cases (Table 2,3). In this system the conductivity increases with the bias applied (Table 1).When the bias of $6 \mathrm{~V}$ is applied, the Goldstone mode completely disappears 
Table 1: Resulting fit parameters

\begin{tabular}{|c|c|c|c|c|c|c|c|}
\hline $\begin{array}{l}\text { Bias } \\
\text { (V) }\end{array}$ & $\operatorname{dim}(n m)$ & Capping & Liquid crystal & cond $(S / \mathrm{cm})$ & $\mathbf{n}$ & cond_err & n_err \\
\hline 0 & 12 & $\mathrm{Au}_{12} @$ pOEGMA & W129 & $1.51043 \cdot 10^{-12}$ & 0.4388 & $1.00649 \cdot 10^{-13}$ & 0.0106 \\
\hline 4 & 12 & $\mathrm{Au}_{12} @$ pOEGMA & W129 & $3.16228 \cdot 10^{-11}$ & 0.8429 & $1.13799 \cdot 10^{-12}$ & 0.0659 \\
\hline $4->0$ & 12 & $\mathrm{Au}_{12} @$ pOEGMA & W129 & $7.90679 \cdot 10^{-12}$ & 0.8659 & $1.17192 \cdot 10^{-13}$ & 2.3202 \\
\hline 0 & 36 & $\mathrm{Au}_{30} @$ pOEGMA & W129 & $2.1707 \cdot 10^{-12}$ & 0.4560 & $1.0105 \cdot 10^{-13}$ & 0.0216 \\
\hline 6 & 36 & $\mathrm{Au}_{30} @$ pOEGMA & W129 & $1.5918 \cdot 10^{-10}$ & 0.7649 & $1.0337 \cdot 10^{-11}$ & 0.0073 \\
\hline $6->0$ & 36 & $\mathrm{Au}_{30} @$ pOEGMA & W129 & // & // & // & // \\
\hline 4 & 36 & $\mathrm{Au}_{30} @$ pOEGMA & W129 & $1.0057 \cdot 10^{-10}$ & 0.9649 & $1.0838 \cdot 10^{-11}$ & 0.0432 \\
\hline $4->0$ & 36 & $\mathrm{Au}_{30} @ \mathrm{pOEGMA}$ & W129 & $1.3658 \cdot 10^{-12}$ & 0.2574 & $\begin{array}{c}1.095757 \cdot 10^{-} \\
13\end{array}$ & 0.011622 \\
\hline 0 & 12 & $\begin{array}{c}\mathrm{Au}_{12} @ \mathrm{MEO} \mathrm{MA}_{90}-\mathrm{co}- \\
\mathrm{pOEGMA}_{10}\end{array}$ & W129 & $1.9319 \cdot 10^{-12}$ & 0.3977 & $\begin{array}{c}1.012403 \cdot 10^{-} \\
13\end{array}$ & 0.014633 \\
\hline 6 & 12 & $\begin{array}{c}\mathrm{Au}_{12} @ \mathrm{MEO}^{2} \mathrm{MA}_{90}-\mathrm{co}- \\
\mathrm{pOEGMA}_{10}\end{array}$ & W129 & $4.2329 \cdot 10^{-10}$ & 0.8127 & $1.06917 \cdot 10^{-11}$ & 0.027654 \\
\hline $6->0$ & 12 & $\begin{array}{c}\mathrm{Au}_{12} @ \mathrm{MEO}^{2} \mathrm{MA}_{90}-\mathrm{co}- \\
\mathrm{pOEGMA}_{10}\end{array}$ & W129 & $4.3591 \cdot 10^{-12}$ & 0.4978 & $1.12414 \cdot 10^{-13}$ & 0.065860 \\
\hline 0 & 12 & $\mathrm{Au}_{12} @$ pOEGMA & W182 & $3.2794 \cdot 10^{-12}$ & 0.5301 & $1.00543 \cdot 10^{-13}$ & 0.011054 \\
\hline & & $\mathrm{Au}_{12} @$ pOEGMA & W182 & $7.2224 \cdot 10^{-10}$ & 0.8938 & $1.02089 \cdot 10^{-11}$ & 0.006688 \\
\hline $4->0$ & 12 & $\mathrm{Au}_{12} @ \mathrm{pOEGMA}$ & W182 & $2.4837 \cdot 10^{-11}$ & 0.6232 & $1.13252 \cdot 10^{-12}$ & 0.061526 \\
\hline
\end{tabular}

(Figure 8C). The three modes, arising from the fit of imaginary part of permittivity at $0 \mathrm{~V}$, degrade in to one, indicative of the inhibition of a dielectric mode. The situation is partially restored when we stop the bias, while a mode reappears at lower frequencies with a larger dielectric increment (Figure 8D).

Figure 9 shows that when the bias is turned off, the system can be restored to the initial conditions. In this case no inhibition of modes is present but a certain memory effect is appreciable.When the GNPs coated with $\mathrm{MEO}_{2} \mathrm{MA}_{90}$ - - 0 -OEGMA brushes are utilized for doping, no memory effect is visible when a bias of $4 \mathrm{~V}$ is applied, indicative of the important role of the capping polymers 


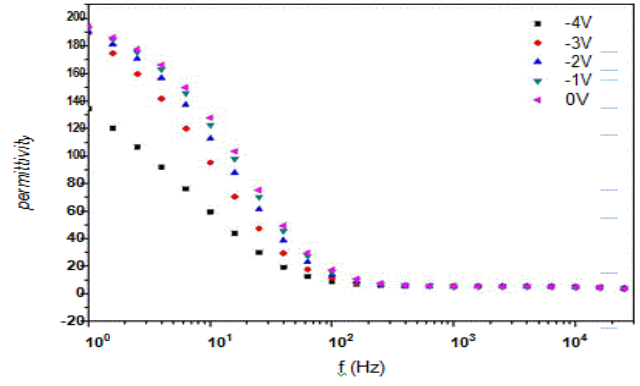

Figure 6: Dielectric permittivity as a function of frequency at $95^{\circ} \mathrm{C}$ after condition dc potential, from -4 to $-1 \mathrm{~V}$ and again $0 \mathrm{~V}(-1 \rightarrow 0 \mathrm{~V})$ of W129 doped with $\mathrm{Au}_{12} @ 0 E G M A$ nanoparticles
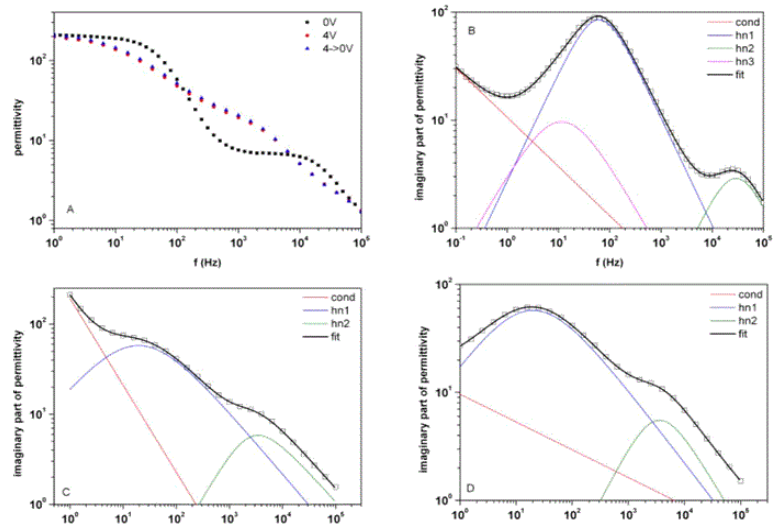

Figure 7: Dielectric permittivity as a function of frequency at $95^{\circ} \mathrm{C}$ at $0 \mathrm{~V}$, at $4 \mathrm{~V}$, again 0V $(4->0 \mathrm{~V})$, of W129 doped with $\mathrm{Au}_{30} @$ polyOEGMA nanoparticles. Imaginary part of permittivity at $0 \mathrm{~V}(\mathrm{~B}), 4 \mathrm{~V}(\mathrm{C}), 4->0 \mathrm{~V}$ (D).
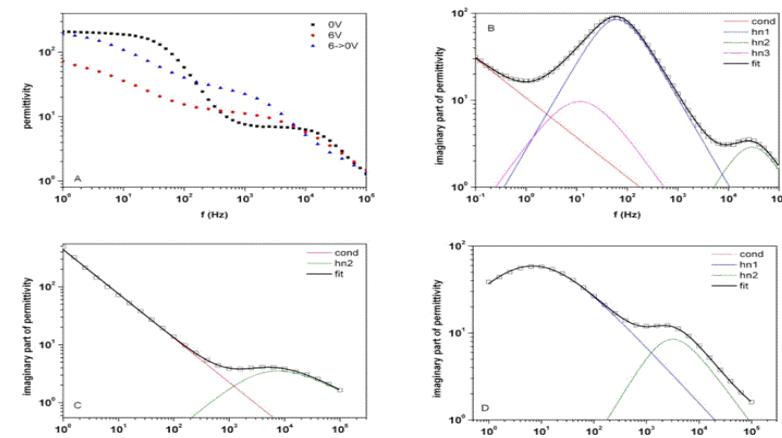

Figure 8: Dielectric permittivity as a function of frequency at $95^{\circ} \mathrm{C}$ at 0V, at 6V, again 0V (6 - > 0V), of W129 doped with $\mathrm{Au}_{30} @$ polyOEGMA nanoparticles.

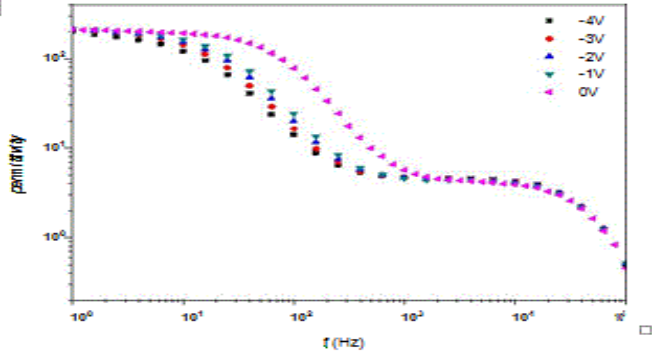

Figure 9: Dielectric permittivity as a function of frequency at $95^{\circ} \mathrm{C}$ after condition dc potential, from -4 to $-1 \mathrm{~V}$ and again $0 \mathrm{~V}(-1->0 \mathrm{~V})$ of W129 doped with $\mathrm{Au}_{30} @$ polyOEGMA nanoparticles.

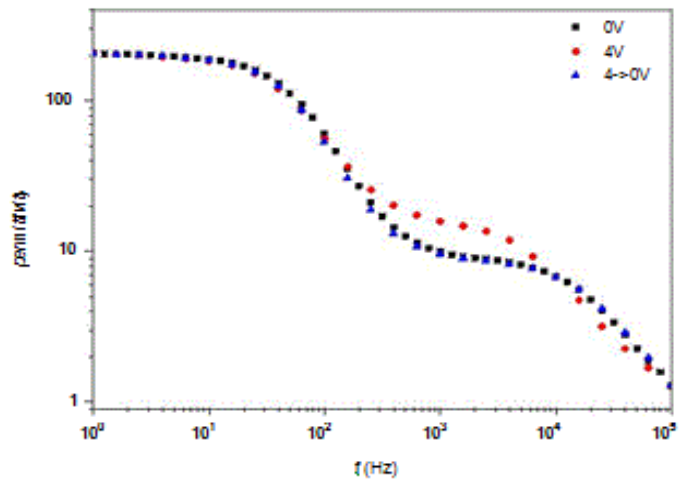

Figure 10: Dielectric permittivity as a function of frequency at $95^{\circ} \mathrm{C}$ at OV, at 4V, again 0V (4 - > 0V), of W129 doped with $\mathrm{Au}_{12} @ \mathrm{MEO}_{2} \mathrm{MA}_{90}-\mathrm{Co}-$ OEGMA $_{10}$ nanoparticles.
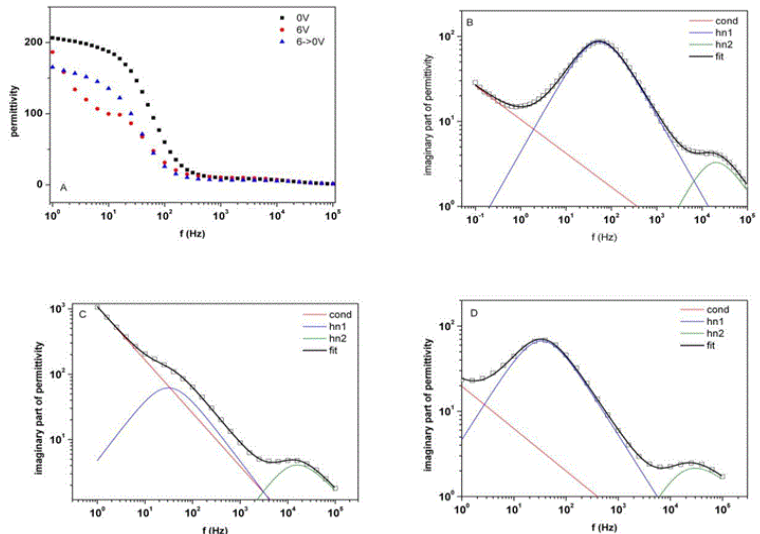

Figure 11: Dielectric permittivity as a function of frequency at $95^{\circ} \mathrm{C}$ at $0 \mathrm{~V}$, at $6 \mathrm{~V}$, again $0 \mathrm{~V}(6->0 \mathrm{~V})$, of W129 doped with $\mathrm{Au}_{12} @ \mathrm{MEO}_{2} \mathrm{MA}_{90}$-coOEGMA $_{10}$ nanoparticles. 
(Figure 10). But the situation is slightly better when 6V is applied.

Figure 11 shows a memory effect in the range of frequencies from 1 to $\sim 100 \mathrm{~Hz}$. In this case there is a shift of the Goldstone and Soft mode to lower frequencies and a reduction of the dielectric increment for the first mode and a slight increase of the increment for the second mode when $6 \mathrm{~V}$ is applied.

In figure 12 the system slowly approaches to initial conditions. The memory effect is quite weak when larger GNPs, namely $\mathrm{Au}_{30} @ \mathrm{MEO}_{2} \mathrm{MA}_{90}$-co-OEGMA ${ }_{10}$. The spectra confirm the influence of the nanoparticles on the behavior (Figure 13, 14 and 15).

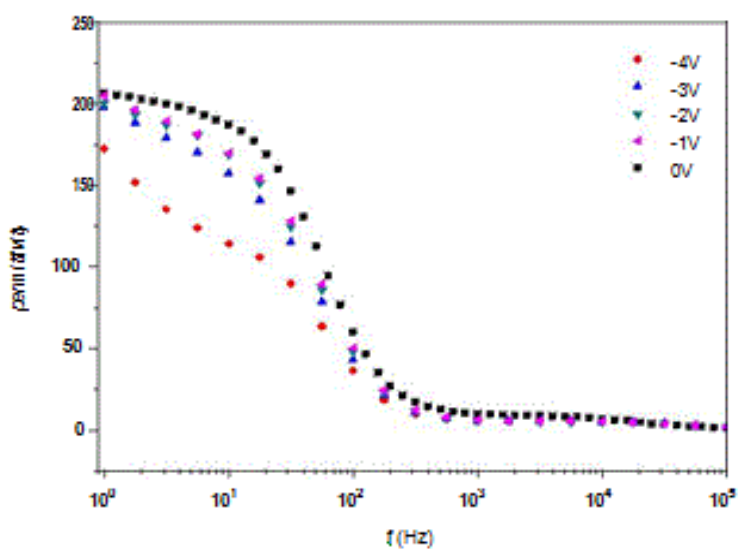

Figure 12: Dielectric permittivity as a function of frequency at $95^{\circ} \mathrm{C}$ after condition dc potential, from -4 to $-1 \mathrm{~V}$ and again $0 \mathrm{~V}(-1->0 \mathrm{~V})$, of W129 doped with $\mathrm{Au}_{30} @ \mathrm{MEO}_{2} \mathrm{MA}_{90}$-co-OEGMA ${ }_{10}$ nanoparticles.

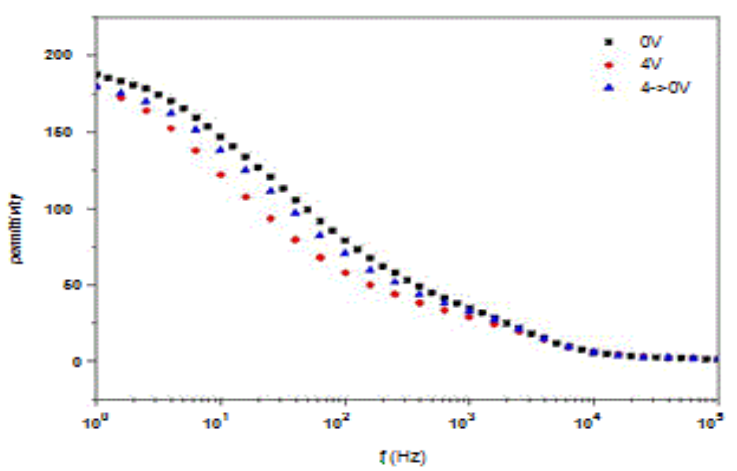

Figure 13: Dielectric permittivity as a function of frequency at $95^{\circ} \mathrm{C}$ at $0 \mathrm{~V}$, at $4 \mathrm{~V}$, again 0V (4 - > 0V), of W129 doped with $\mathrm{Au}_{30} @ \mathrm{MEO}_{2} \mathrm{MA}_{90}-$ co-OEGMA $_{10}$ nanoparticles.

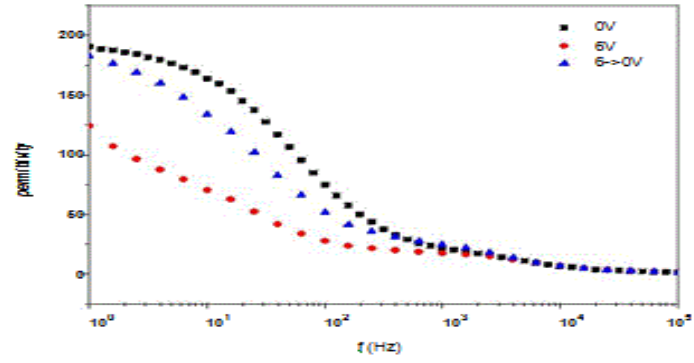

Figure 14: Dielectric permittivity as a function of frequency at $95^{\circ} \mathrm{C}$ at 0V, at 6V, again 0V (6 - > 0V), of W129 doped with $\mathrm{Au}_{30} @ \mathrm{MEO}_{2} \mathrm{MA}_{90}-$ co-OEGMA ${ }_{10}$ nanoparticles.

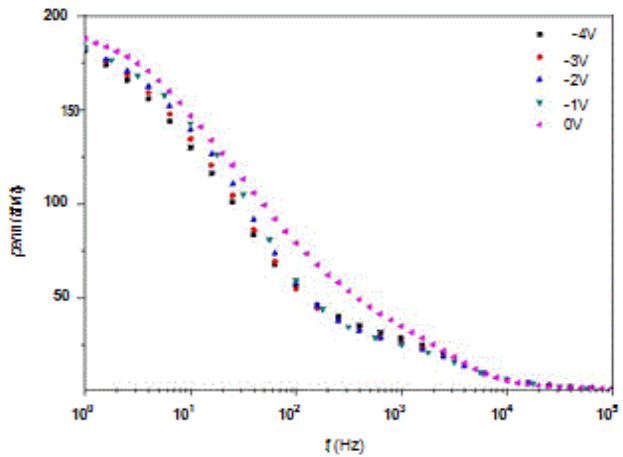

Figure 15: Dielectric permittivity as a function of frequency at $95^{\circ} \mathrm{C}$ after condition dc potential, from -4 to $-1 \mathrm{~V}$ and again $0 \mathrm{~V}(-1 \rightarrow 0 \mathrm{~V})$ of W129 doped with $\mathrm{Au}_{30} @ \mathrm{MEO}_{2} \mathrm{MA}_{90}$-co-OEGMA 10 nanoparticles.

\section{Results with W182 Liquid Crystal}

Distinct from W129, W182 doesn't show memory effect when we apply a voltage of $4 \mathrm{~V}$ figure 16 .

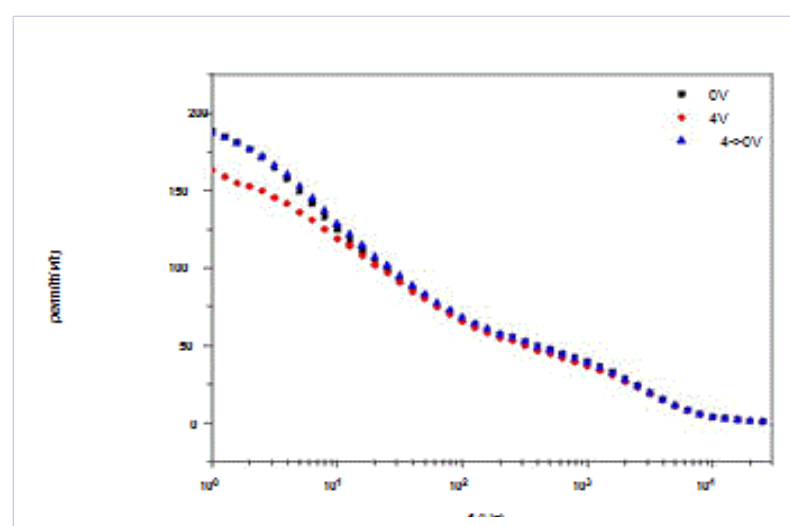

Figure 16: Dielectric permittivity as a function of frequency at $105^{\circ} \mathrm{C}$ at $0 \mathrm{~V}$, at $4 \mathrm{~V}$, again $0 \mathrm{~V}(4->0 \mathrm{~V})$, of Pure $\mathrm{W} 182$. 
Table 2: Resulting fit parameters.

\begin{tabular}{|c|c|c|c|c|c|c|c|c|c|c|}
\hline Bias (V) & $\operatorname{dim}(n m)$ & capping & Liquid crystal & Hn1_f1 & $\Delta \varepsilon 1$ & a1 & b1 & Hn1_err & $\Delta \varepsilon 1$ err & a1_err \\
\hline 0 & 12 & $\mathrm{Au}_{12} @$ pOEGMA & W129 & 31.499 & 139.93 & 0.8577 & 1 & 1.0064 & 0.6864 & 0.0031 \\
\hline 4 & 12 & $\mathrm{Au}_{12} @$ pOEGMA & W129 & 14.589 & 97.899 & 0.9509 & 1 & 1.0972 & 13.099 & 0.0280 \\
\hline $4->0$ & 12 & $\mathrm{Au}_{12} @$ pOEGMA & W129 & 19.722 & 65.253 & 0.9940 & 1 & 1.3617 & 61.685 & 0.0802 \\
\hline 0 & 36 & $\mathrm{Au}_{30} @$ pOEGMA & W129 & 62.114 & 169.69 & 1 & 1 & 1.0103 & 3.1379 & 0 \\
\hline 6 & 36 & $\mathrm{Au}_{30} @$ pOEGMA & W129 & // & // & // & // & // & // & // \\
\hline 6- > 0 & 36 & $\mathrm{Au}_{30} @$ pOEGMA & W129 & 6.8769 & 210.13 & 0.6503 & 1 & 1.0148 & 1.1808 & 0.0042 \\
\hline 4 & 36 & $\mathrm{Au}_{30} @$ pOEGMA & W129 & 19.454 & 189.47 & 0.6966 & 1 & 1.0764 & 8.4209 & 0.0111 \\
\hline 4- > 0 & 36 & $\mathrm{Au}_{30} @ \mathrm{pOEGMA}$ & W129 & 18.518 & 184.24 & 0.7217 & 0.9425 & 1.0553 & 2.1266 & 0.0131 \\
\hline 0 & 12 & $\begin{array}{c}\mathrm{Au}_{12} @ \mathrm{MEO}_{2} \mathrm{MA}_{90}- \\
\text { co-pOEGMA } \\
10\end{array}$ & W129 & 53.627 & 187.85 & 0.9427 & 1 & 1.0098 & 1.5022 & 0.0052 \\
\hline 6 & 12 & $\begin{array}{c}\mathrm{Au}_{12} @ \mathrm{MEO}_{2} \mathrm{MA}_{90}- \\
\text { co-pOEGMA } \\
10\end{array}$ & W129 & 31.274 & 131.30 & 0.9609 & 1 & 1.1084 & 18.712 & 0.0313 \\
\hline $6->0$ & 12 & $\begin{array}{c}\mathrm{Au}_{12} @ \mathrm{MEO}_{2} \mathrm{MA}_{90}- \\
\text { co-pOEGMA } \\
10\end{array}$ & W129 & 33.969 & 140.85 & 0.9682 & 1 & 1.0197 & 3.7925 & 0.0142 \\
\hline 0 & 12 & $\mathrm{Au}_{12} @ \mathrm{pOEGMA}$ & W182 & 9.8077 & 188.48 & 0.8771 & 0.6874 & 1.0169 & 1.0586 & 0.0073 \\
\hline 4 & 12 & $\mathrm{Au}_{12} @$ pOEGMA & W182 & 31.323 & 100.72 & 1 & 1 & 1.0302 & 4.0439 & 0 \\
\hline $4->0$ & 12 & $\mathrm{Au}_{12} @$ pOEGMA & W182 & 33.481 & 204.47 & 0.9862 & 1 & 1.0354 & 8.9623 & 0.0192 \\
\hline
\end{tabular}

From -3 to $-1 \mathrm{~V}$ the permittivity values are almost identical. A conditioning of the sample occurs when we apply different values of condition potential in comparison with the initial state (Figure 17). Figure 18 show that the doping of 12 nm nanoparticles, namely, $\mathrm{Au}_{12} @$ polyOEGMA, induces a memory effect visible in the middle area of the spectrum. The shift in frequency of the Goldstone mode at higher frequency is present and a complessive reduction of the dielectric increment as in the previous cases. Parameters a and b indicate a Debye mode when we apply a voltage of $4 \mathrm{~V}$ and turn off it, and the fit results indicate

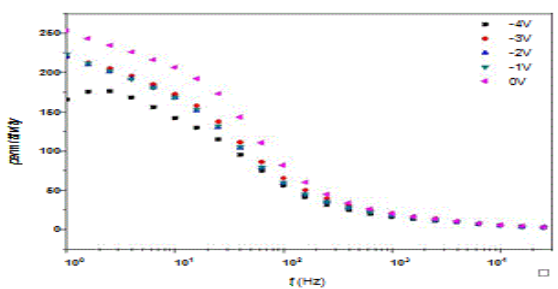

Figure 17 :Dielectric permittivity as a function of frequency at $105^{\circ} \mathrm{C}$ after condition dc potential, from -4 to $-1 \mathrm{~V}$ and again $0 \mathrm{~V}(-1->0 \mathrm{~V})$ of pure W182. 


\section{Comparisons on Different Liquid Crystals Doped with Various Sized Gold Nanoparticles for onvolatileMemory Effects}

Table 3: Resulting fit parameters.

\begin{tabular}{|c|c|c|c|c|c|c|c|c|c|c|c|}
\hline Bias (V) & $\operatorname{Dim}(n m)$ & capping & $\begin{array}{l}\text { Liquid } \\
\text { crystal }\end{array}$ & Hn2_f2 & $\Delta \varepsilon 2$ & a2 & b2 & Hn2_err & $\Delta \varepsilon 2 \_$err & a2_err & b2_err \\
\hline 0 & 12 & $\begin{array}{l}\mathrm{Au}_{12} @ \mathrm{pOE} \\
\mathrm{GMA}\end{array}$ & W129 & 5242.8 & 12.768 & 1 & 0.7526 & 1.0217 & 0.10069 & 0 & 0.0408 \\
\hline 4 & 12 & $\mathrm{Au}_{12} @$ pOEGMA & W129 & 27171.3 & 5.5458 & 1 & 0.9104 & 1.0727 & 0.1243 & 0 & 0.06305 \\
\hline $4->0$ & 12 & $\mathrm{Au}_{12} @$ pOEGMA & W129 & 26697.46 & 5.45986 & 1 & 0.8814 & 1.0321 & 0.05967 & 0 & 0.02747 \\
\hline 0 & 36 & $\mathrm{Au}_{30} @$ pOEGMA & W129 & 29173.59 & 5.76553 & 1 & 1 & 1.0123 & 0.05276 & 0 & 0 \\
\hline 6 & 36 & $\mathrm{Au}_{30} @$ pOEGMA & W129 & 4646.757 & 11.56474 & 0.8092 & 0.6403 & 1.2732 & 0.31688 & 0.06638 & 0.13117 \\
\hline $6->0$ & 30 & $\mathrm{Au}_{30} @$ pOEGMA & W129 & 2706.26 & 18.47879 & 1 & 0.8243 & 1.0717 & 0.96825 & 0 & 0.06074 \\
\hline 4 & 30 & $\mathrm{Au}_{30} @$ pOEGMA & W129 & 2472,29 & 14.18827 & 1 & 0.6572 & 1.0537 & 0.58011 & 0 & 0.01197 \\
\hline $4->0$ & 30 & $\mathrm{Au}_{30} @$ pOEGMA & W129 & 3254.77 & 11.65696 & 1 & 0.8813 & 1.0546 & 0.55731 & 0 & 0.03451 \\
\hline 0 & 12 & $\begin{array}{c}\mathrm{Au}_{12} @ \mathrm{MEO}_{2} \mathrm{MA}_{90} \text {-co- } \\
\text { pOEGMA }_{10}\end{array}$ & W129 & 17810.66 & 7.078790 & 1 & 0.8393 & 1.0686 & 0.16307 & 0 & 0.04455 \\
\hline 6 & 12 & $\begin{array}{c}\mathrm{Au}_{12} @ \mathrm{MEO}_{2} \mathrm{MA}_{90}-\mathrm{co}- \\
\text { pOEGMA }_{10}\end{array}$ & W129 & 13281.59 & 9.066902 & 1 & 0.7933 & 1.0654 & 0.20226 & 0 & 0.03539 \\
\hline $6->0$ & 12 & $\begin{array}{c}\mathrm{Au}_{12} @ \mathrm{MEO}_{2} \mathrm{MA}_{90}-\mathrm{co}- \\
\text { pOEGMA }_{10}\end{array}$ & W129 & 17680.72 & 5.966177 & 1 & 0.5161 & 1.1432 & 0.46426 & 0 & 0.06858 \\
\hline 0 & 12 & $\begin{array}{l}\mathrm{Au}_{12} @ \mathrm{pOE} \\
\mathrm{GMA}\end{array}$ & W182 & 5523.06 & 10.2773 & 1 & 0.8352 & 1.2639 & 0.17185 & 0 & 0.01038 \\
\hline 4 & 12 & $\mathrm{Au}_{12} @ \mathrm{pOE}$ GMA & W18 2 & 22844.9 & 5.46708 & 1 & 0.9464 & 1.0458 & 0.07584 & 0 & 0.03497 \\
\hline $4->0$ & 12 & $\mathrm{Au}_{12} @ \mathrm{pOE}$ GMA & W18 2 & 25084. 2 & 5.01678 & 1 & 0.9776 & 1.1235 & 0.26375 & 0 & 0.09136 \\
\hline
\end{tabular}
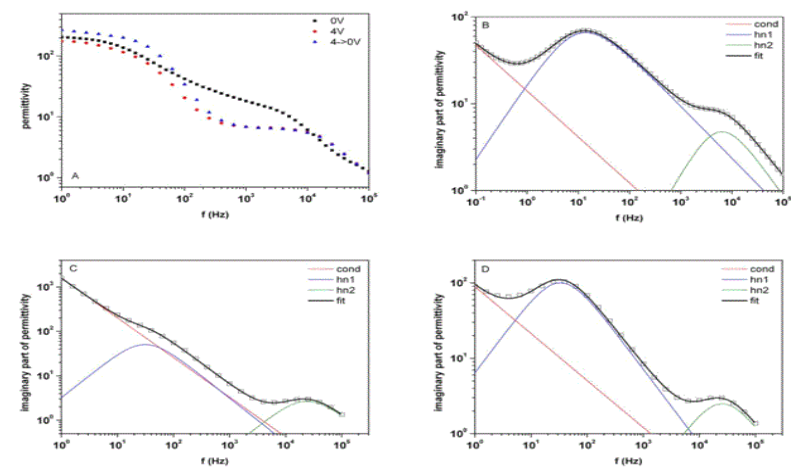

Figure 18: Dielectric permittivity as a function of frequency at $105^{\circ} \mathrm{C}$ at $0 \mathrm{~V}$, at $4 \mathrm{~V}$, again $0 \mathrm{~V}(4->0 \mathrm{~V})$, of W182 doped with $\mathrm{Au}_{12} @$ polyOEGMA nanoparticles

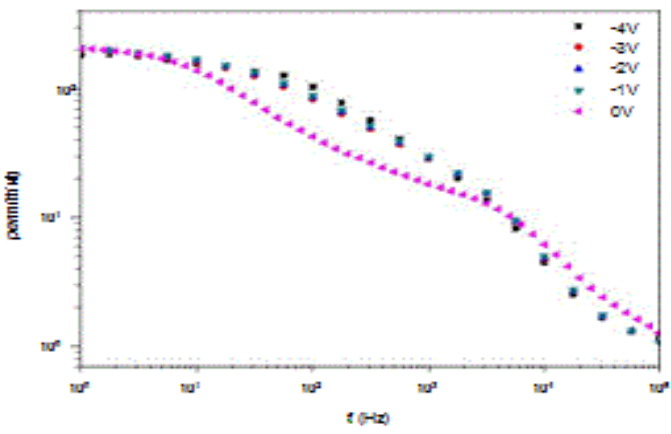

Figure 19: Dielectric permittivity as a function of frequency at $105^{\circ} \mathrm{C}$ after condition dc potential, from -4 to $-1 \mathrm{~V}$ and again $0 \mathrm{~V}(-1->0 \mathrm{~V})$ of W182 doped with $\mathrm{Au}_{12} @$ polyOEGMA nanoparticles. 


\section{Comparisons on Different Liquid Crystals Doped with Various Sized Gold Nanoparticles for onvolatileMemory Effects}

By applying the condition potential they obtained results indicate a strange behavior in the range of frequencies from 10 to $10^{3} \mathrm{~Hz}$ in particular (Figure 19). This behavior cannot be rationalized by the data from the analysis of the imaginary part. The doping of the large GNPs namely, $\mathrm{Au}_{30} @$ polyOEGMA increases the memory effect, thus leading to a diametrically opposite result different from that obtained with W129 (Figure 20).

When the GNPs coated with $\mathrm{MEO}_{2} \mathrm{MA}_{90}$-co-OEGMA brushes are used for doping, no memory effects are observed (Figure 21 and 23)

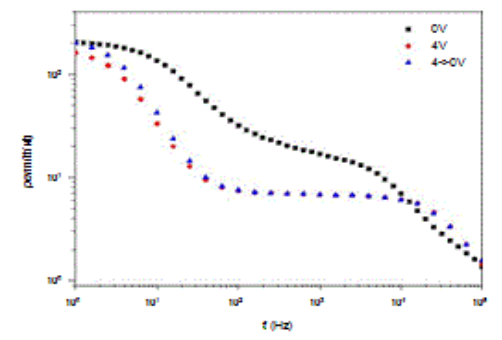

Figure 20: Dielectric permittivity as a function of frequency at $105^{\circ} \mathrm{C}$ at $0 \mathrm{~V}$, at $4 \mathrm{~V}$, again $0 \mathrm{~V}(4->0 \mathrm{~V})$, of $\mathrm{W} 182$ doped with $\mathrm{Au}_{30} @$ polyOEGMA nanoparticles.

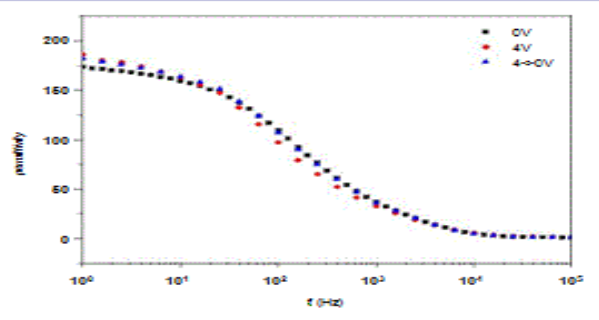

Figure 21: Dielectric permittivity as a function of frequency at $105^{\circ} \mathrm{C}$ at $0 \mathrm{~V}$, at $4 \mathrm{~V}$, again $0 \mathrm{~V}(4->0 \mathrm{~V})$, of $\mathrm{W} 182$ doped with $\mathrm{Au}_{30} @ \mathrm{MEO}-$ ${ }_{2} \mathrm{MA}_{90}$-co-OEGMA ${ }_{10}$ nanoparticles.

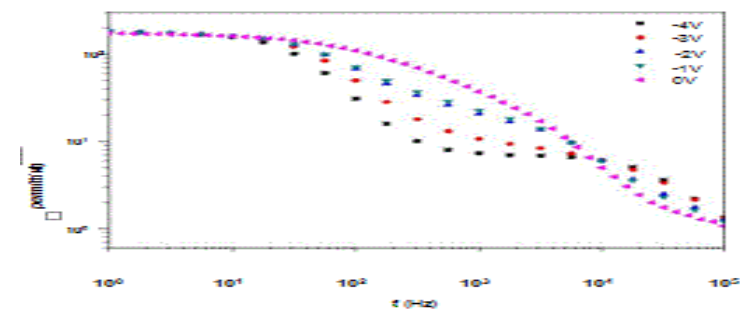

Figure 22: Dielectric permittivity as a function of frequency at $105^{\circ} \mathrm{C}$ after condition dc potential, from -4 to $-1 \mathrm{~V}$ and again $0 \mathrm{~V}(-1->0 \mathrm{~V})$ of W128 doped with $\mathrm{Au}_{30} @ \mathrm{MEO}_{2} \mathrm{MA}_{90}$-co-OEGMA 10 nanoparticles.

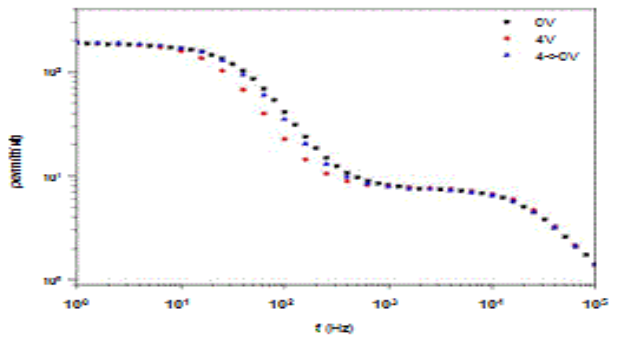

Figure 23: Dielectric permittivity as a function of frequency at $105^{\circ} \mathrm{C}$ at $0 \mathrm{~V}$, at $4 \mathrm{~V}$, again $0 \mathrm{~V}(4->0 \mathrm{~V})$, of $\mathrm{W} 128$ doped with $\mathrm{Au}_{30} @ \mathrm{MEO}$ ${ }_{2} \mathrm{MA}_{90}$-co-OEGMA ${ }_{10}$ nanoparticles.

for both large and small GNPs. The memory effect has been observed for several days in pure and in the doped ferroelectric mixtures. In fact a partial return to starting condition is possible only when the doped mixture is heated to isotropic phase and then cooled. For a better comprehension of the mechanisms induced by nanoparticles, the imaginary part of permittivity in function of frequency or dielectric loss spectra should be considered during ferroelectric phase for pure liquid crystal mixture and for the doped one.

The doping of GNPs to ferroelectric LCs led to a shift in the dielectric loss peaks to higher or lower frequencies. The shift in the frequency for the Soft mode indicates a change in the relaxation time for the reorientation of the molecules of the LC components, $t=1 / 2 p f$, while the shift in the frequency for the Goldstone mode indicates a more or less rapid phase fluctuation in the azimuthal orientation of the director. This variation in frequency with the addition of gold nanoparticles may be due to the change in rotational viscosity [9].

Since GM is related to the fluctuations of the helix in $\mathrm{SmC}^{*}$ phase, GM contribution is maximum when the helix is undistorted. Helix distortion in any manner will lead to suppression of GM and the decrease in dielectric permittivity and GM strength; in other terms this decrease can be understood on the basis of molecular interaction between ferroelectric LC and gold nanoparticles [10-12]. Usually it is assumed that doping with gold nanoparticles enhances the disorder in ferroelectric LC. In order to obtain frequency relaxation values and dielectric increments, experimental data were fitted by the HavriliakNegami function with the addition of a conductivity contribution [13]. As it was observed in the past nanoparticles produce large local electric fields, which polarize the liquid-crystal molecules and thereby increase the intermolecular interaction [14-15].

\section{Conclusions}

The dielectric spectroscopy has revealed the electrical partially reversible bistable behaviour, which could be useful for technological applications, in particular for digital nonvolatile memory devices. Memory effects have not been observed in all 
systems with different kind of nanoparticles and liquid crystal, which is confirming the importance of the hosting liquid crystal and of the chemical nature and properties of gold nanoparticles.

\section{Acknowledgement} Alfredo Pane.

The authors gratefully appreciate the assistance of $\mathrm{Dr}$

\section{References}

1.Chandrasekhar S. Liquid Crystals. Cambridge:Cambridge University Press. 2nd ed. 1992.

2.Hegmann T, Qi H, Marx VM. Nanoparticles in liquid crystals: synthesis, self-assembly, defect formation and potential applications. Journal of Inorganic and Organometallic Polymers and Materials. 2007;17(3):483-508. doi: 10.1007/s10904-007-9140-5

3.Prakash J, Choudhary A, Kumar A, Mehta DS, Biradar AM. Nonvolatile memory effect based on gold nanoparticles doped ferroelectric liquid crystal. Appl Phys Lett. 2008;93(11):112904. doi: $10.1063 / 1.2980037$

4.Marino L, Marino S, Wang D, Bruno E, Scaramuzza N. Nonvolatile memory effects in an orthoconic smectic liquid crystal mixture doped with polymer-capped gold nanoparticles. Soft Matter. 2014;10(21):3842-3849. doi: 10.1039/c4sm00377b

5.Edwards EW, Chanana M, Wang D, Mohwald H. Stimuli-Responsive Reversible Transport of Nanoparticles Across Water/Oil Interfaces. Angewandte Chemie International Edition. 2008;47(2):320-323. doi: 10.1002/anie.200702597

6.Lutz JF. Polymerization of oligo(ethylene glycol) (meth) acrylates: Toward new generations of smart biocompatible materials. Journal of Polymer Science Part A: Polymer Chemistry. 2008;46(11):34593470. doi: 10.1002/pola.22706

7.Xia H, Bai S, Hartmann J, Wang D. Synthesis of monodisperse quasi-spherical gold nanoparticles in water via silver(I)-assisted citrate reduction. Langmuir. 2010;26(5):3585-3589. doi: 10.1021/ la902987w

8.Zhang P, Xi C, Feng C, Xia H, Wang D, Tao X. Transition metal ion assisted synthesis of monodisperse, quasi-spherical gold nanocrystals via citrate reduction. Cryst Eng Comm. 2014;16:5268-5274. doi: 10.1039/C4CE00334A

9.Hiller S, Biradar AM, Wrobel S, Haase W. Dielectric behavior at the smectic-C*-chiral-nematic phase transition of a ferroelectric liquid crystal. Phys Rev E. 1996;53(1):641-649.

10.Neeraj, Kumar P, Raina KK. Analysis of Dielectric and Electrooptic Responses of Nanomaterials Doped Ferroelectric Liquid Crystal Mixture. J Mater Sci Technol. 2011;27(12):1094-1098.
11.Biradar AM, Kilian D, Wrobel S, Haase W. A sub-hertz frequency dielectric relaxation process in a ferroelectric liquid crystal material. Liq Crys. 2000;27(2):225-231. doi: 10.1080/026782900203029

12.Mandal PK, Lapanik A, Wipf R, Stuehn B, Haase W. Subhertz relaxation process in chiral smectic mixtures doped with silver nanoparticles. Appl Phys Lett. 2012;100(7):073112. doi: $10.1063 / 1.3685700$

13.Havriliak SJ, Negami SA. A complex plane representation of dielectric and mechanical relaxation processes in some polymers. Polymer. 1967;8:161-210. doi: 10.1016/0032-3861(67)90021-3

14.Li F, Buchnev O, Cheon CI, Glushchenko A, Reshetnyak V, Reznikov Y, et al. Orientational coupling amplification in ferroelectric nematic colloids. Phys Rev Lett. 2006;97(14):147801. doi: 10.1103/ physrevlett.97.147801

15.Li F, Buchnev O, Cheon CI, Glushchenko A, Reshetnyak V, Reznikov Y, et al. Orientational Coupling Amplification in Ferroelectric Nematic Colloids. Phys Rev Lett. 2007;99:219901. doi: 10.1103/physrevlett.97.147801 